outwards. The membrane through which this current occurs may be looked upon, in its connexion with the carbonic acid of venous blood, as a colloid mass or colloid septum free from pores, through which carbonic acid has to pass on its way out of the lungs, and oxygen on its way into the blood. Now, Prof. Graham has shown that acids which form with bases crystallisable compounds, such as hydrochloric and nitric acids, have the power of diffusing themselves very readily into a colloid mass, and of passing with very great rapidity into water through a thin colloid septum. We may, therefore, expect that carbonic acid, which forms with bases highly crystallisable compounds, will, when in solution, be possessed of diffusible properties in a considerable degree. It may consequently, I think, be safely considered that the passage of carbonic acid from the blood through the tissue of the lungs is due to a phenomenon of liquid diffusion of the dissolved gas, and accelerated by the high temperature of the body and the current produced by the evaporation of moisture at the surface of the lungs.

We have now to account for the evolution of carbonic acid into the air chambers or vesicles. To explain this phenomenon, the reader has merely to bear in mind the very familiar fact, that by heating water containing carbonic acid the gas is expelled from it. I have attempted to show by what process carbonic acid contained in venous blood reaches the external surface of the lungs ; we may now assume that it simply evaporates from the heat of the body, along with the moisture subsequently found in the breath.

Air is constantly being renewed in the pulmonary cavity, so that the carbonic acid which evaporates at the surface of the lungs is in a great measure carried away at each expira. tion. Should the amount of air inspired be insufficient to remove the carbonic acid from the air vesicles, the gas will accumulate therein, and diffuse itself back again into the moist membrane and into the blood. Graham has shown that gases diffuse themselves through colloid septa in which they are soluble; and as carbonic acid is comparatively soluble in water, it will be taken up readily by a membrane moistened with an aqueous solution, and delivered into the blood.

The evolution of carbonic acid at the lungs may be considered as regulated by four different means :-

1. The amount of carbonic acid contained in the blood.

2. The degree of readiness with which the dissolved carbonic acid permeates the tissue of the lungs.

3. The temperature of the lungs.

4. The amount of air taken into the lungs at each inspiration.

In the state of health, the exit of carbonic acid from the body is thus perfectly regulated; but should any of these conditions for the normal elimination of this gas be deficient or in any way altered, as from some disease of the tissue of the lungs, or from the temperature of the body being depressed, or from the volume of air inspired being too small, then carbonic acid will be retained and accumulate in the blood, adding to the existing disease.

The absorption of exygen by the lungs must, I believe, be considered, according to Graham's discovery, as due to the solubility of oxygen in the colloid pulmonary membrane at the temperature of the lungs; and I conceive it as finding its way into the blood by a process of diffusion, just as carbonic acid moved out of it, and somewhat in the same way as rain-water is distributed throughout the soil of a field (a process which is, however, one of distribution by porosity), to be finally carried away by the drains. If there is enough oxygen in air to saturate the pulmonary membrane, the inhalation of oxygen gas as a means of introducing more of it into the blood will fail; but should this tissue be capable of holding more oxygen in solution than is supplied to it by the air inspired, then we may expect beneficial results from the treatment.

According to the present view, the absorption of oxygen by the lungs will depend upon and be regulated by the readiness with which the oxygen inspired is taken up or absorbed by the membrane of the lungs, and the rate at which it diffuses itself into the blood. A thickening or other morbid state of the lungs, by interfering with the absorption and diffusion of oxygen throughout their tissue, will, it may reasonably be expected, add to the constitutional disorder by impeding the admiasion of oxygen into the blood: it is important to bear in mind this circumstance for the rational treatment of this class of diseases.

I beg to remain, Sir, your obedient servant,

Harleyostreet, Jan。 18th, 1867,

\section{COMPENSATION FOR RAILWAY INJURIES.}

\author{
To the Editor of THE LANCET.
}

Sir,-Dr. Reynolds may not have gone so far as the other two witnesses whose names have been mentioned, but certainly made statements which along with theirs led the jury to regard the case as so serious, and to give such large damages (f4700). According to what was stated at the trial, the plaintiff should by this time be either dead or dying; and when I said that, on the contrary, he admitted his being quite well, I did not intend to allege that he had done so in words, since this would have been a degree of ingenuousness hardly to be expected under the circumstances. When I heard that this person's late agent (Mr. Officer) had reported so favourably of his health; when I heard that his late medical attendant (Mr. Balfour), who resides in the same town, had frequently seen him walking about apparently quite well; and when $I$ heard that on the day before Christmas, having come from Portobello to Edinburgh, he had publicly appeared in the crowded jury court during a trial in which he had no personal interest, I did not suppose that he could any longer profess to remain on the sick list; and I still think that he cannot properly do so, however inconsistent this opinion may be with the flippant remarks of Dr. Reynolds, and the lawyer who has come to his assistance.

I am, Sir, your obedient servant,

Edinburgh, Jan. 28th, 1867.

JAMES SYME

\section{To the Editor of THE LANCET.}

SIR,-In your issue of January 5th I observe a communica. tion from Mr. Syme on the subject of Compensation for Rail. way Injuries. With his views in regard to the injustice of the legal enactments of our country, and the unsatisfactory character of the verdicts of juries upon claims for compensation on account of personal injuries, or the illustration he gives in support of his views by reference to the somewhat famous case of Denham $v$. the Great Northern Railway Com. pany, I have nothing to do. In the case "of medical diversity that has just occurred here," as Mr. Syme somewhat quaintly terms it, I have, however, a personal concern, seeing that the so-called "surgeon of experience in such cases" was myself. This must be my excuse for trespassing on your valuable space, and requesting to be allowed to give your readers and the profession generally the facts of the case, upon which they may base their own conclusions. In so doing I only respond to Mr. Syme's wish for the "publication of cases exhibiting an entire discrepancy between the medical evidence," and shall be glad if I can thus assist "to check the reckless advocacy of one-sided views."

On the 28th of April last I was requested to visit a com. mercial traveller at his hotel. On calling I found him lying upon a couch in his bedroom. He complained of pain in his head and back, in consequence of a railway concussion two days previously, near Berwick-upon-Tweed. He stated that when the accident occurred he was thrown violently forwards, then backwards, and on recovering his senses found himself lying upon the floor of the carriage; that on reaching Berwick by omnibus he walked about half a mile (not a mile and a half, as Mr. Syme states) to see Dr. Maclagan, who, Mr. Syme says, "assured the patient that there was no local injury or occasion for confinement" but who, in a statement furnished by him of the evidence he was prepared to give at the trial, states his opinion as follows, "It seemed to me that Mr.

thought all risk was over, but that was not my opinion. I recommended him to take complete rest for some days. As a physician I should certainly say that a person receiving a shock such as Mr. - did, would not feel the effects of it immediately so much as he would do some days after the shock, and that was my reason for recommending perfect rest for a time." The patient having, notwithstanding, come on to Edinburgh, went, by the advice of his hotel-keeper to consult Mr. Syme. In his evidence given upon oath at the trial the claimant stated: "Mr. Syme requested me to return home and foment my back with flannel and hot water, and that in a few days I would know what was the matter ;" a somewhat irreconcileable statement with that of Mr. Syme, who found "there was no local complaint"-(Why then did he recom. mend hot fomentations to the back?) - and concluded that "if he felt any uneasiness it must be more mental than 
bodily." (The hot fomentations were no doubt intended to allay the mental irritation !)

Dissatisfied with the superficial, and, as he thought, careless examination of his case by $\mathrm{Mr}$. Syme, the patient sent immediately for me, not by the advice of his law agent, as Mr. Syme would have it, but, as he stated to me, in pursuance of his original intention on coming to Edinburgh.

On examining into his symptoms I found that the pain experienced in the head he described as though a cord was tied tightly round his temples, and as if a constant throbbing affected his whole head, but chiefly the vertex. This pain was increased on motion of the head or body, and upon firm closure of the jaws. He also complained of giddiness and nausea on changing his position, and of pain, on pressure, just below the occiput. On examining his naked back I found no marks of bruise. He moved stiffly as one mass in rising from the recumbent or sitting posture and on walking, and com plained of pain in his loins. On stooping in the sitting posture he bent his dorsal and cervical vertebre, but kept his lumbar spine rigid, and rested with his hands on his knees. In walking he carried his superincumbent weight rigidly, and kept his arms fixed close by his sides. In standing he supported his weight equally on both feet, and could not bear to stand on one limb or to hop. On examining the lumbar region, where he complained of pain, I found no change in the line of the lumbar spine, nor pain in the lumbar muscles, but marked pain on pressure over all the spinous processes of the lumbar vertebræ, especially over the third, and along the line of both, but especially the right, sacro-iliac synchondrosis. In every mode of examination the pain was persistently referred to the same parts. He further complained of restless uneasiness at night, and cramps in the limbs, especially on the right side, keeping him from sleeping, with frightful dreams, which awaked him when he fell asleep. His pulse was feeble. He complained of an uneasy sensation in the precoruium, and fluttering heart's action. I put him under careful treatment ; and on the 9 th of May, as the symptoms, local and general, continued, and the patient further complained of the right foot being benumbed, and of great urinary irritability, I asked Prof. Spence, the "trustworthy coadjutor" alluded to by Mr. Syme, to visit him with me. Mr. Spence coincided in my view of the case, and we thereafter jointly signed a certificate in which we designated the injury "a severe wrench of the spine and sacro-iliac synchondroses." This certificate enabled his "accomplished agent" to stimulate the somewhat tardy attention of the railway company to the fact of his being injured, and brought their medical officer, Dr. Dunsmure, to call on him. Dr. Dunsmure's view of the injury at this period of the case, as stated by the claimant on oath, was as follows:- "When Dr. Dunsmure first saw me he told me that I had got a severe knock on the back, and that the muscles of the back were injured, and that I would in future require to be careful, as $I$ would always be subject to rheumatism in the injured part of the back." He also said "that my nervous system had received a shock."

Upon the 12th of June Dr. Dunsmure called in on behalf of the railway company his "trustworthy coadjutor," Mr. Syme. Of this visit the claimant says on oath: "They looked at my naked back but never touched it. Professor Syme never on any occasion touched it."

On the 18th of June, by the advice of Professor Spence and myself, the patient was removed in a carriage to Portobello, a watering place three miles from Edinburgh. After his arrival there, in spite of repose and warm salt-water douche bathing in his bedroom, his symptoms became aggravated, and blistering was had recourse to.

On the 17th of July, while the blistered surface was still tender and the symptoms of pain in the back and uneasiness in the right limb and bladder continued, I was informed that the trial of the patient's action against the Railway Company would come on within the ensuing fortnight. In these circum stances I felt it to be my duty to forbid him to go to Edinburgh to attend the trial, and granted him a certificate " on soul and eonscience" (the usual Scotch formulary) that he was unfit to appear in court to be examined. In consequence of my certificate the trial was delayed, I believe by consent of parties. Mr. Syme must be under some entire misapprehension as to the nature of his employment on this occasion, which, I am informed, was certainly not by the court; it may have been by the Railway Company, but no report, I am told, other than my own was produced or read to the court

By the loth of August there was little or no pain along the line of the sacro-iliac synchondroses. The pain in the lumbar region on motion of any kind was, however, greatly increased, and the third lumbar spinous process was now observed to be unduly prominent. In consultation with Professor Spence it was decided that the Corrigan cautery should be severely applied to the back, iodide of potassium given internally, and complete repose maintained. By the 12th of September the improvement in the spinal symptoms led us to recommend the use of the salt water douche bath at a neighbouring bathing establishment.

On the 12th of December, in anticipation of the trial, Professor Spence and myself, having stripped the patient carefully, examined him. We found rigidity of the lumbar spine, prominence of the spinous process of the third lumbar vertebra, persistent pain on motion or percussion in this situation, inability to maintain the erect posture for more than a quarter of an hour without aggravation of the suffering, continued urinary irritability, and coldness of the right lower extremity.

I may further mention that Dr. Gillespie examined the patient on several occasions through the autumn, and coincided in the opinions expressed in regard to this case by Pro. fessor Spence and myself.

I also made repeated and careful experimental inquiries into the temperature, sensibility, and muscular contractibility of the extremities in this case, and found a persistent difference of five degrees, a marked difference by the compass test in the sensibility, and a manifest want of muscular irritability in the right limb as compared with the left.

The trial took place in the end of December, and resulted in the Railway Company, after the examination of the claimant himself, and one other non-professional witness, consenting to a verdict of $£ 1000$, without the jury being called on to consider the case.

As Mr. Syme deems the results of such cases, in regard to the claimant's "speedy recovery of health, worthy of attention," I may add that since the trial the patient has been removed to the country. The journey prostrated him for five days so completely that he could not move out of bed, and so far from being well he is obliged to continue the same repose and to maintain persistent counter-irritation by means of blistering tissue to relieve himself of pain. I deem it unnecessary to add anything further, save to suggest, after the manner of Mr. Syme, the following questions :-

1. Is it not the case, in patients who have sustained a wrench of the spine, that serious symptoms are sometimes long of manifesting themselves, and that for the first few days after such accidents the patient may go about unconscious of the damage he has sustained ?

2. Does a rigid lumbar spine, persistent pain on movement or percussion in the site of the third lumbar vertebra, and undue prominence of its spinous process, persistent numbness and coldness of one lower extremity as estimated by instruments that cannot falsify, with general languor, sleeplessness at night, continued urinary irritability, point to anything less than a very serious injury inflicted upon the spinal column?

I have the honour to be, Sir, your obedient servant, Edinburgh, Jan. 20th, 1867. Patrick Heron Watsor.

\section{THE INDIAN MEDICAL SERVICE.}

\section{To the Editor of THE LANCET.}

SIR,-Permit me to commend to your notice the articles in the Indian Medical Gazette of the 1st of November, and that of the Englishman, from which the editor of the Medical Gazette quotes on the subject of Lord Cranborne's dispatch promulgating arrangements for the organisation of the administrative staff of the British and Indian medical forces. Words fail to convey the bitter sense of disgust and disappointment which pervades all ranks of the old Indian service. That service is in fact extinct, the prizes are all wrested from us, and the prospects of those who from necessity still hold to the service are of the most gloomy nature. Perhaps no case more fully illustrates this fact than my own. I entered the service in 1840. I have never quitted the country, nor have I been a day absent from my duty except on two occasions for short periods of sixty and thirty days respectively. I was for years associated with the European branch of the army, having held medical charge both of artillery and infantry, and was of those removed by the orders which deprived Indian surgeons of European charges. I am completing my twenty-seventh year of service, and, under the old scale of appointments of the administrative grade, might reasonably have looked for promotion in two, or at the outside three years. In other words, 